\title{
Are those in need taking dietary supplements? A survey of 21923 adults
}

\author{
R. A. Harrison ${ }^{1,4 *}$, D. Holt ${ }^{1}$, D. J. Pattison ${ }^{3}$ and P. J. Elton ${ }^{2}$ \\ ${ }^{1}$ Bolton Primary Care Trust, St Peter's House, Silverwell Street, Bolton BL1 1PP, UK \\ ${ }^{2}$ Bury Primary Care Trust, Silver Street, Bury BL9 OEN, UK \\ ${ }^{3}$ ARC Epidemiology Unit, Stopford Building, University of Manchester, Oxford Road, Manchester M13 9PT, UK \\ ${ }^{4}$ Evidence for Population Health Unit, University of Manchester, Oxford Road, Manchester M13 9PT, UK
}

(Received 12 July 2003 - Revised 10 November 2003 - Accepted 21 November 2003)

\begin{abstract}
Many people take dietary supplements, but information on characteristics associated with their use is lacking. The relationship between lifestyle behaviours, morbidity and use of dietary supplements has not been examined and earlier studies have limited applicability to a general population. These issues were addressed in the current study. Information was obtained by postal questionnaire sent to a sample of the general population. The questionnaire was completed by $70.5 \%$ of the sample (15 465 from a total sample of 21923 ), with at least onethird $(35.5 \%)$ taking dietary supplements. In adjusted analyses, supplement users were more likely to be women, white, home-owners, non-smokers and physically active. Use of vitamin, mineral and/or antioxidant supplements was associated with eating more fruits and vegetables, and taking fish-oil supplements was associated with eating oil-rich fish. A history of CVD or risk factors for CVD reduced the risk of taking vitamins, minerals and/or antioxidants or fish-oil supplements. Those reporting musculoskeletal disorders such as arthritis were more likely to take fish-oil supplements For the first time, we have shown that dietary supplement use is related to different types of morbidity. In particular, people at risk of primary or secondary CVD seem less likely to use dietary supplements, despite possible benefits shown in clinical trials. Public health organisations need to develop guidelines for the public and health professionals regarding the uncontrolled use of dietary supplements in the community.
\end{abstract}

Dietary supplements: Inverse care: Epidemiology: Consumer characteristics

The use of dietary supplements has increased dramatically over the past 10 years, despite a lack of consensus regarding any benefits at a population level (Nesheim, 1999; Willett \& Stampfer, 2001). Up to $50 \%$ of adults take at least one dietary supplement (Finch et al. 1998; Kirk et al. 1999; Balluz et al. 2000; Henderson et al. 2002), and in the UK $40 \%$ of women and $29 \%$ of men now take a dietary supplement, compared with $17 \%$ of women and $9 \%$ of men 15 years ago (Gregory et al. 1990; Henderson et al. 2002).

Members of the public expect dietary supplements purchased over the counter to have proven benefits (Jong et al. 2003), while being unaware of possible harm from taking some of these products (Rothman et al. 1995; Melhus et al. 1998; Ross et al. 2000; Favreau et al. 2002; Waters et al. 2002; Michaëlsson et al. 2003; Palmer et al. 2003). Clinical trials have found certain supplements to have a positive effect on health for discrete groups in the population (for examples, see MRC Vitamin Study Research Group, 1991; Chandra, 1992; Heikinheimo et al. 1992), but these findings may not be applicable to the entire adult population. Products used in clinical trials can also differ with respect to dose and quality compared with those available in high-street stores.

Previous work suggests that people taking dietary supplements participate in healthy lifestyles and have favourable diets in terms of disease prevention (Kirk et al. 1999; Frank et al. 2000; Messerer et al. 2001; Jong et al. 2003). However, few studies have examined the relationship between specific types of dietary supplements and morbidity and lifestyles in any detail. Furthermore, no single study in the UK has addressed this question across men and women of all ages. These issues were addressed in the current study, forming the largest population-based study on this topic for adults of all ages in the UK.

\begin{abstract}
Methods
Data were collected using a self-completion postal questionnaire sent to a $5 \%$ sample of people aged $\geq 18$ years living in the metropolitan boroughs of Bolton and Wigan in north-west England, UK. Participants were identified from the general practice register at the local health authority using systematic sampling. The register included the
\end{abstract}


details of everyone who lived within the geographical boundaries of the boroughs of Bolton and Wigan and was registered with a general practitioner. A covering letter explained the purpose of the survey and a pre-paid business franked addressed envelope was included to return the questionnaire (Harrison et al. 2002). Nonresponders were sent a reminder postcard 1 week later, and a further copy of the survey 1 week after that. The local research ethics committee approved the study.

To find out who took dietary supplements, and which ones they took, participants were asked, 'Do you usually take any of these supplements?'. Participants could select the response 'none' if they did not take any dietary supplements, or indicate against a given list which supplements they took (vitamins, minerals, antioxidants, codliver oil, pure fish-oil). For completeness, they could also add any other dietary supplements to the list. In the analysis, dietary supplements were categorised as either fishoil-based supplements or those based on any combinations of vitamins, minerals and/or antioxidants. Information on health and lifestyle behaviours was elicited using questions adapted from the Health Survey for England and from local surveys previously carried out in the north-west region of England (Department of Health, 2003). Self-rated assessment of health in the past year was coded as good, excellent or fair/poor. The twelve-item general health questionnaire was used to identify psychiatric problems, indicated by a score $\geq 4$ (Goldberg \& Hillier, 1979). Questions on specific illness relied on self-report and included having a history of the following in the past year: arthritis; recurring backache, sciatica, lumbago; bronchitis; asthma (shortness of breath with wheezing); angina (severe chest pain or discomfort on exertion). Participants were asked to indicate if they currently had, or had ever had, high blood pressure or diabetes, or whether a doctor had ever told them that they had had a heart attack or stroke. A final health question asked if they were taking any prescribed medications. Subjects were defined as physically active if they participated in moderate or vigorous activity for at least $15 \mathrm{~min}$ on three or more occasions per week (Godin \& Shephard, 1985). Participants were also asked if they smoked, how many portions of fruits and vegetables they ate in an average day and how many portions of oilrich fish (excluding tinned tuna) they ate each week. They were asked to indicate their ethnic group and housing tenure was used to indicate socio-economic status (excluding residential accommodation or student halls).

Data were analysed using SPSS (version 11.0.1; SPSS Inc., Chicago, IL, USA). Crude and adjusted odds ratios (OR) with $95 \%$ CI were calculated using binary logistic regression for the strength of association between supplement use and various lifestyle and dietary factors. The adjusted analyses included, where appropriate, age, gender and housing tenure. The risk of taking vitamin, mineral and/or antioxidant supplements was also adjusted for eating at least five portions of fruits and/or vegetables per $\mathrm{d}$. The risk of taking fish-oil supplements was adjusted for eating at least one portion of oil-rich fish per week. In the logistic regression, age was treated as a continuous variable unless stated and all other variables were dichotomised.

\section{Results}

The survey was posted to 21923 adults in 2001 and 15465 $(70.5 \%)$ were returned completed. Of the responders, $45.2 \%$ were men and the overall mean age was 49.8 years. The mean age of responders was 8.3 years greater than non-responders. The ethnic mix was (\%): white 95.5; Asian 3.5; black, Chinese or mixed race 1.0. This was re-grouped in the analysis as white or non-white. Current smoking was reported by $27 \cdot 6 \%$. More than one-half of all respondents $(57.7 \%)$ were not physically active. Only $12.6 \%$ reported eating at least five portions of fruits and vegetables per $\mathrm{d}$ and $43.5 \%$ ate at least one portion of oil-rich fish per week. The percentage of respondents living in privately owned accommodation was 79.3.

\section{Supplement use}

Over one-third of respondents $(35.4 \%)$ indicated that they usually took at least one dietary supplement, of whom $72.2 \%$ were taking one product and $27.8 \%$ taking two or more different products. The use of any dietary supplement was greater among older people, women, homeowners, non-smokers, those who were physically active, and those describing their ethnic group as white (Table 1). The use of vitamin, mineral and/or antioxidant supplements was positively associated with eating at least five portions of fruits and vegetables per d (28.7v. $21.4 \%$; adjusted OR 1.41, $95 \%$ CI 1.26, 1.58). Similarly, taking fish-oil supplements was higher among those eating one portion or more of oil-rich fish per week (28.3 v. 18.4\%; adjusted OR 1.50, $95 \%$ CI 1.37, 1.63).

\section{Health}

The use of any type of dietary supplements was positively associated with self-rated health, but there was no apparent association with psychiatric morbidity or taking prescribed medication (Table 1).

When restricted to the type of supplements taken, no relationship was observed between the use of antioxidant, vitamin and/or mineral supplements and having selfreported arthritis, recurring backache, bronchitis or asthma (Table 2). However, people with a history of angina, high blood pressure, diabetes, a heart attack or stroke were less likely to be taking antioxidant, vitamin and/or mineral supplements than those who did not report these conditions. A similar pattern was observed for the use of fish-oil supplements, with several exceptions. First, no association was observed between using fish-oil supplements and a history of high blood pressure. Second, the use of fish-oil supplements was found to be positively associated with having arthritis or recurring backache, lumbago or sciatica. These relationships between the use of specific dietary supplements and disease remained after controlling separately for the dietary intake of fruits and vegetables and oil-rich fish (Table 3).

\section{Discussion}

We used a population health and lifestyle survey to examine the relationship between dietary supplement use, 


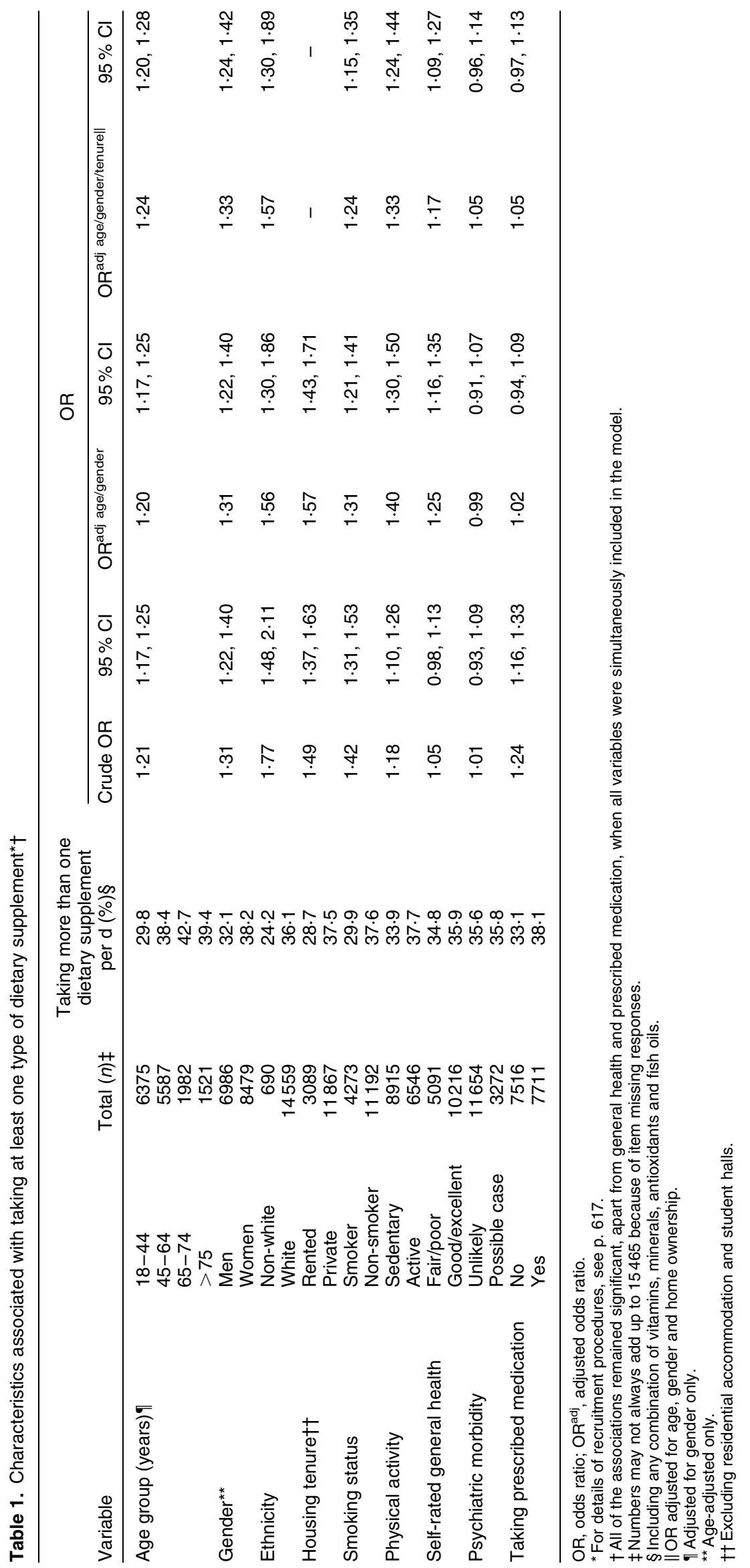


R. A. Harrison et al.

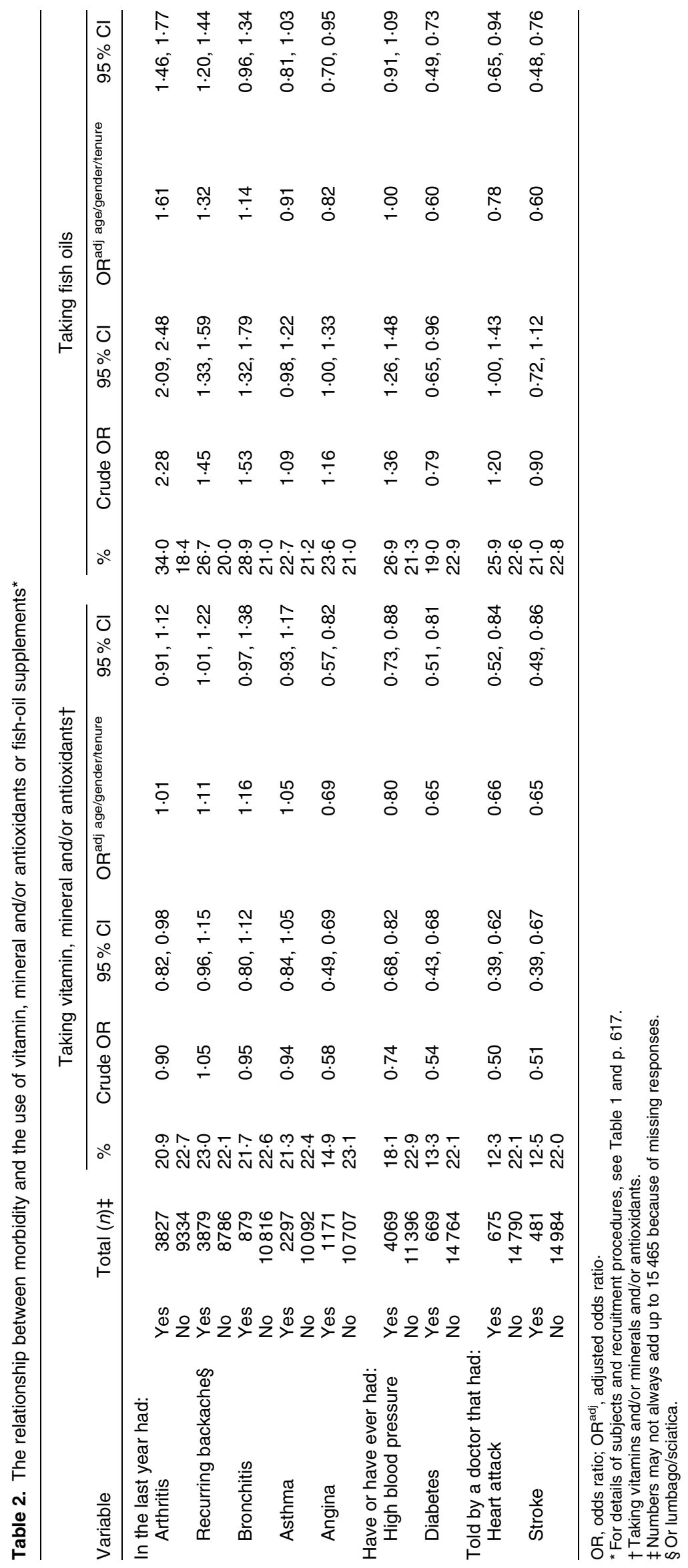


Table 3. The effect of adjusting for dietary information on morbidity and the use of vitamin, mineral and/or antioxidant, or fish-oil supplements

\begin{tabular}{|c|c|c|c|c|}
\hline & \multicolumn{2}{|c|}{$\begin{array}{l}\text { Taking vitamin, } \\
\text { mineral and/or } \\
\text { antioxidants }\end{array}$} & \multicolumn{2}{|c|}{$\begin{array}{l}\text { Taking fish-oil } \\
\text { supplements }\end{array}$} \\
\hline & $\mathrm{OR}^{\mathrm{adj}} \dagger$ & $95 \% \mathrm{Cl}$ & $\mathrm{OR}^{\mathrm{adj}} \neq$ & $95 \% \mathrm{Cl}$ \\
\hline \multicolumn{5}{|c|}{ In the last year had: } \\
\hline Angina & 0.70 & $0.58,0.83$ & 0.80 & $0.68,0.95$ \\
\hline Arthritis & 1.02 & $0.91,1.13$ & 1.65 & $1.48,1.83$ \\
\hline Backache & $1 \cdot 11$ & $1.01,1.22$ & 1.32 & $1.19,1.45$ \\
\hline \multicolumn{5}{|c|}{ Have or have ever had: } \\
\hline $\begin{array}{l}\text { High blood } \\
\text { pressure }\end{array}$ & $0 \cdot 81$ & $0.73,0.89$ & 1.00 & $0.91,1.11$ \\
\hline Diabetes & 0.62 & $0.49,0.79$ & 0.62 & $0.49,0.78$ \\
\hline Heart attack & 0.66 & $0.52,0.85$ & 0.85 & $0.68,1.05$ \\
\hline Stroke & 0.61 & $0.45,0.83$ & 0.63 & $0.48,0.83$ \\
\hline
\end{tabular}

OR, odds ratio; $\mathrm{OR}^{\text {adj }}$, adjusted odds ratio.

* For details of subjects and recruitment procedures, see Table 1 and p. 617. †OR adjusted for age, gender, home ownership, and eating at least five portions of fruits and vegetables per $d$.

‡OR adjusted for age, gender, home ownership and eating at least one portion of oil-rich fish per week.

morbidity and lifestyle factors. The large sample size and good response rate to the questionnaire added to the precision and wider applicability of our results. Having said that, we cannot discount the possibility that factors associated with the use of dietary supplements might differ among those who did not complete the survey.

In any study it is important to consider the validity and reliability of the assessment methods. Previous work has found lifestyle surveys can have good measurement properties, but we did not have resources to test directly the questionnaire used in our present study (Ishihara et al. 2001; Murphy et al. 2002; Satia-Abouta et al. 2003). There is also a tendency for people to over-report their intake of 'healthy' foods such as fruits and vegetables (Black \& Cole, 2001), although this is less likely for fish consumption (Cook et al. 2000). This may have occurred in our present study, but it is unlikely to have introduced systematic bias in the associations with the use of dietary supplements. As with all cross-sectional studies, our present findings only show associations and do not inform cause-effect relationships, which need confirming in longitudinal studies or randomised controlled trials (Elwood, 1998). We suggest that our present study could have underestimated the use of dietary supplements at any one point in time and also across the year. A study in the USA found that dietary supplement use from written self-report was $30.5 \%$, increasing to $61.0 \%$ when the 200 participants underwent face-to-face interviews (Hensrud et al. 1999). Counter to this, in the current study participants were asked if they 'usually' took dietary supplements. This did not include a time frame and may have included people who had taken supplements in the past, and would take them again in the future, for example when they had a cold. We also suggest that prevalence estimates for users of dietary supplements will change depending upon the time of year when the survey is carried out. The main purpose of our present study was to identify associations between users and non-users of dietary supplements, rather than providing accurate prevalence estimates relating to their use at the time that the survey was conducted. There is no consensus on the way to collect information on the use of dietary supplements and such measurement issues require further research.

The number of people we observed using dietary supplements and the increased usage in women and older people has been reported in previous studies in the UK (Finch et al. 1998; Kirk et al. 1999; Henderson et al. 2002) and USA (Balluz et al. 2000). The positive relationship with higher social class, for which we used home ownership as a proxy, is also consistent with these studies. Few studies have compared the use of dietary supplements within different ethnic groups. Results from the National Health and Nutrition Examination Survey III (Balluz et al. 2000) have demonstrated that white people were more likely to be using dietary supplements. We also found that dietary supplement use was lower among people from an ethnic group, of whom the majority were South Asian. However, it is unlikely that these findings are applicable to all ethnic groups. In the Multiethnic Cohort Study in Hawaii and Los Angeles (USA; Foote et al. 2003), of the 100196 people reporting no chronic disease, the use of multivitamins was highest among Japanese Americans $(63.6 \%)$ compared with whites $(60.5 \%)$, and lowest among Latinos $(41.6 \%)$ and African Americans (49.6\%).

The fact that people eating the recommended intakes of fruits and vegetables, or oil-rich fish, were more likely to take vitamin, mineral and/or antioxidants or fish-oil supplements is consistent with a study in women (Kirk et al. 1999), thus questioning the need for additional nutritional supplementation in the majority of people who already take dietary supplements. The current study extends this to include men and its relationship with morbidity and lifestyle behaviours. We found that with the exception of arthritis and back problems, people taking any dietary supplements were less likely to have or have had a chronic disease or acute event. We also found that users of any dietary supplements were less likely to smoke and were more likely to be involved in regular physical activity. It was not possible in our present survey to examine the use of dietary supplements among people with or having had cancer. This was because cancer was thought to be too sensitive an issue to include in postal questionnaires. However, the survey did provide information on the use of dietary supplements among people with a range of chronic and acute diseases, which had varying risks in terms of mortality.

The only specific health problem or disease in which we found a positive association with the use of any dietary supplements was for fish oils and their increased use among people with self-reported musculoskeletal disease. Evidence from clinical trials supports the use of fish-oil supplements for people with rheumatoid arthritis, as the long-chain $n-3$ fatty acids can improve symptoms such as joint pain and swelling (Fortin et al. 1995). However, we found no published evidence from clinical trials for using fish oils in the treatment of recurring backache, lumbago or sciatica.

Our present study found that people with risk factors for, or existing CVD were less likely to be taking any dietary 
supplements, even after adjusting for their intake of fruits, vegetables and oil-rich fish. Yet evidence for the benefits of fish-oil supplementation in relation to CHD is well established. For example, clinical trials have found large reductions in CHD and all-cause mortality among survivors of myocardial infarction who were given fishoil supplements (Singh et al. 1997; GISSI-Prevenzione Investigators, 1999). The benefits from using fish oils in primary prevention of CHD are less certain (Bucher et al. 2002). We recognise that many clinical trials of fish oils used doses larger than those obtained from following the manufacturers' recommended intakes of fish-oil supplements when purchased over the counter. Consequently, we cannot be sure that over-the-counter supplements would have similar effects to those observed in the clinical studies.

Detailed information on the reasons why people did or did not take dietary supplements was not collected as part of the present study. A study in women found that the use of dietary supplements was influenced by the beliefs and attitudes of individuals to health and care-seeking behaviours (Conner et al. 2001). Hence, our present results suggest that people with $\mathrm{CHD}$, or at risk of CHD, are less likely to have positive care-seeking behaviours compared to people with arthritis. This in itself could contribute to this multifactorial disease, given its strong link with unhealthy lifestyles (Magnus \& Beaglehole, 2001), and thereby having implications for health promotion.

Guidelines for the general use of dietary supplements lack consensus. The British Dietetic Association (Arens, 1999) and the American Dietetic Association (1994) argue that undernutrition is unlikely in people with a good quality balanced diet and only recommend vitamin and/or mineral supplements in particular circumstances, when benefits have been established. An extensive review by the US Preventive Services Task Force (2003) concludes that there is insufficient evidence to promote or discourage the use of vitamins $\mathrm{A}, \mathrm{C}$ or $\mathrm{E}$, multivitamins with folic acid, or antioxidant combinations to reduce the risk of cancer or CVD. Others argue that it is 'prudent' for the majority of adults to take some form of vitamin supplements given the possibility of undernutrition (Tripp, 1997; Willet \& Stampfer, 2001; Fairfield \& Fletcher, 2002; Fletcher \& Fairfield, 2002). Yet taking dietary supplements is not without a risk of adverse effects (Rothman et al. 1995; Melhus et al. 1998; Ross et al. 2000; Favreau et al. 2002; Waters et al. 2002; Michaëlsson et al. 2003; Palmer et al. 2003); we suggest that existing surveillance systems might be inadequate in quantifying the true extent of this.

To conclude, we provide further support for the 'inverse supplement hypothesis'. We have extended this and for the first time examined associations with morbidity and lifestyle factors, finding that supplement use is higher among healthy people living healthy lifestyles. We also found differences in the use of dietary supplements depending on the existence of specific morbidity and this behaviour does not appear to be influenced by existing scientific evidence. We would like to see local healthcare providers develop policies regarding the use of dietary supplements and to disseminate this information to consumers. This needs to include information on risks of adverse events while pointing out clearly those groups of people most likely to benefit from taking specific types of dietary supplements. However, such information should not detract in any way from emphasising the importance of eating the source materials themselves.

\section{References}

American Dietetic Association (1994) Position of the American Dietetic Association: Enrichment and fortification of foods and dietary supplements. J Am Diet Assoc 94, 661-663.

Arens U (1999) Vitamin and mineral supplementation. Position paper of the British Dietetic Association. J Hum Nutr Diet 12, 171-178.

Balluz LS, Kieszak SM, Philen RM \& Mulinare J (2000) Vitamin and mineral supplement use in the United States. Results from the third National Health and Nutrition Examination Survey. Arch Fam Med 9, 258-262.

Black A \& Cole T (2001) Biased over- or under-reporting is characteristic of individuals whether over time or by different assessment methods. J Am Diet Assoc 101, 70-80.

Bucher HC, Hengstler P, Schindler C \& Meier G (2002) n-3 Polyunsaturated fatty acids in coronary heart disease: a metaanalysis of randomized controlled trials. Am J Med 112, 298-304.

Chandra R (1992) Effect of vitamin and trace-element supplementation on immune responses and infection in elderly subjects. Lancet 340, 1124-1127.

Conner M, Kirk SF, Cade JE \& Barrett JH (2001) Why do women use dietary supplements? The use of the theory of planned behaviour to explore beliefs about their use. Soc Sci Med 52, 621-633.

Cook A, Pryer J \& Shetty P (2000) The problem of accuracy in dietary surveys. Analysis of the over 65 UK National Diet and Nutrition Survey. J Epidemiol Comm Health 54, 611-616.

Department of Health (2003) Health survey for England. Available: http://www.doh.gov.uk/public/summary.htm (accessed November 2003)

Elwood M (1998) Critical Appraisal of Epidemiological Studies and Clinical Trials. Oxford: Oxford University Press.

Fairfield KM \& Fletcher RH (2002) Vitamins for chronic disease prevention in adults, scientific review. J Am Med Assoc 287, 3116-3126.

Favreau J, Ryu M, Braunstein G, et al. (2002) Severe hepatotoxicity associated with the dietary supplement LipoKinetix. Ann Intern Med 136, 590-595.

Finch S, Doyle W, Lowe C, Bates CJ, Prentice A, Smithers G \& Clarke PC (1998) National Diet and Nutrition Survey: people aged 65 years and over. Report of the Diet and Nutrition Survey, Vol. 1. London: H.M. Stationery Office.

Fletcher RH \& Fairfield KM (2002) Vitamins for chronic disease prevention in adults, clinical applications. J Am Med Assoc 287, 3127-3129.

Foote J, Murphy S, Wilkens L, Hankin J, Henderson B \& Kolonel L (2003) Factors associated with dietary supplement use among healthy adults of five ethnicities. Am $J$ Epidemiol 157, 888-897.

Fortin P, Liang M, Wright E, Beckett L, Chalmers T \& Sperling $R$ (1995) Validation of a meta-analysis, the effects of fish oil in rheumatoid arthritis. J Clin Epidemiol 48, 1379-1390.

Frank E, Bendich A \& Denniston M (2000) Use of vitamin-mineral supplements by female physicians in the United States. Am J Clin Nutr 72, 969-975. 
GISSI-Prevenzione Investigators (1999) Dietary supplementation with $n-3$ polyunsaturated fatty acids and vitamin $\mathrm{E}$ after myocardial infarction: results of the GISSI-Prevenzione trial Lancet 354, 447-455.

Godin G \& Shephard R (1985) A simple method to assess exercise behavior in the community. Can J Appl Sport Sci 10, $141-146$.

Goldberg D \& Hillier V (1979) A scaled version of the General Health Questionnaire. Psychol Med 9, 139-145.

Gregory J, Foster K, Tyler H \& Wiseman M (1990) The Dietary and Nutritional Survey of British Adults. London: H. M. Stationery Office.

Harrison R, Holt D \& Elton P (2002) Do postage stamps increase response rates to postal health surveys? A randomised controlled trial. Int J Epidemiol 31, 871-872.

Heikinheimo R, Inkovaara J, Harju EJ, Haavisto MV, Kaarela RH, Kataja JM, Kokko AM, Kolho LA \& Rajala SA (1992) Annual injection of vitamin D and fractures of aged bone. Calcif Tissue Int 51, 105-110.

Henderson L, Gregory J \& Swan G (2002) The National Diet and Nutrition Survey: Adults Aged 19 to 64 Years, vol. 1, London: H. M. Stationery Office.

Hensrud DD, Engle DD \& Scheitel SM (1999) Underreporting the use of dietary supplements and nonprescription medications among patients undergoing a periodic health examination. Mayo Clin Proc 74, 443-447.

Ishihara J, Sobue T, Yamamoto S, Sasaki S, Akabane M \& Tsugane S (2001) Validity and reproducibility of a self-administered questionnaire to determine dietary supplement users among Japanese. Eur J Clin Nutr 55, 360-365.

Jong N, Ocké M, Branderhorst H \& Friele R (2003) Demographic and lifestyle characteristics of functional food consumers and dietary supplement users. Br J Nutr 89, 273-281.

Kirk S, Cade J, Barrett J \& Conner M (1999) Diet and lifestyle characteristics associated with dietary supplement use in women. Public Health Nutr 2, 69-73.

Magnus P \& Beaglehole R (2001) The real contribution of the major risk factors to the coronary epidemic, time to end the "only-50\%" myth. Arch Intern Med 161, 2657-2660.

Melhus H, Michaelsson K \& Kindmark A (1998) Excessive dietary intake of vitamin $\mathrm{A}$ is associated with reduced bone mineral density and increased risk for hip fracture. Ann Intern Med 129, 770-778.

Messerer M, Johansson SE \& Wolk A (2001) Sociodemographic and health behaviour factors among dietary supplement and natural remedy users. Eur J Clin Nutr 55, 1104-1110.
Michaëlsson K, Lithell H, Vessby B \& Melhus H (2003) Serum retinol levels and the risk of fracture. New Engl J Med 348, 287-294.

MRC Vitamin Research Study Group (1991) Prevention of neural tube defects, results of the Medical Research Council Vitamin study. Lancet 338, 131-137.

Murphy S, Wilkens L, Hankin J, Foote J, Monroe K, Henderson B \& Kolonel LN (2002) Comparison of two instruments for quantifying intake of vitamin and mineral supplements: A brief questionnaire versus three 24-hour recalls. Am J Epidemiol 156, 669-675.

Nesheim MC (1999) What is the research base for the use of dietary supplements? Public Health Nutr 2, 35-38.

Palmer M, Haller C, McKinney P, et al. (2003) Adverse events associated with dietary supplements: an observational study. Lancet 361, 101-106.

Ross EQ, Szabo NJ \& Tebbett IR (2000) Lead content of calcium supplements. J Am Med Assoc 284, 1425-1429.

Rothman K, Moore L, Singer M, Nguyen E-SD, Mannino S \& Milunsky A (1995) Teratogenicity of high vitamin A intake. New Engl J Med 333, 1369-1373.

Satia-Abouta J, Patterson RE, King IB, Stratton KL, Shattuck AL, Kristal AR, Potter JD, Thornquist MD \& White E (2003) Reliability and validity of self-report of vitamin and mineral supplement use in the vitamins and lifestyle study. Am J Epidemiol 157, 944-954.

Singh RB, Niaz MA, Sharma JP, Kumar R, Rastogi V \& Moshiri M (1997) Randomized, double-blind, placebo-controlled trial of fish oil and mustard oil in patients with suspected acute myocardial infarction, the Indian experiment of infarct survival. Cardiovasc Drugs Ther 11, 485-491.

Tripp F (1997) The use of dietary supplements in the elderly, current issues and recommendations. J Am Diet Assoc 97, S181-S183.

US Preventive Services Task Force (2003) Routine Vitamin Supplementation to Prevent Cancer and Cardiovascular Disease, Recommendations and Rationale. June 2003. Agency for Healthcare Research and Quality, Rockville, MD. http://www. ahrq gov/clinic/3rduspstf/vitamins/vitaminsrr.htm (accessed 14 July 2003).

Waters D, Alderman E, Hsia J, et al. (2002) Effects of hormone replacement therapy and antioxidant vitamin supplements on coronary atherosclerosis in postmenopausal women. $J \mathrm{Am}$ Med Assoc 288, 2432-2440.

Willett W \& Stampfer M (2001) What vitamins should I be taking doctor? New Engl J Med 345, 1819-1824. 